"NOTICE: this is the author's version of a work that was accepted for publication in Composite Structures. Changes resulting from the publishing process, such as peer review, editing, corrections, structural formatting, and other quality control mechanisms may not be reflected in this document. Changes may have been made to this work since it was submitted for publication. A definitive version was subsequently published in COMPOSITE STRUCTURES, VOL 94, ISSUE 5, APRIL 2012, PAGES 1555-1563, DOI: 10.1016/j.compstruct.2011.12.017”

\title{
Structural behaviour of composite sandwich panels with plain and fibre- reinforced foamed concrete cores and corrugated steel faces
}

\author{
E.A. Flores-Johnson ${ }^{1}$, Q.M. Li $^{2, *}$ \\ ${ }^{1}$ Institute of Materials Engineering, Australian Nuclear Science and Technology Organisation \\ Locked Bag 2001, Kirrawee DC, NSW, 2232 Australia \\ ${ }^{2}$ School of Mechanical, Aerospace and Civil Engineering, The University of Manchester \\ Pariser Building, Manchester M13 9PL, UK
}

\begin{abstract}
This paper studies the four-point bending response and failure mechanisms of sandwich panels with corrugated steel faces and either plain or fibre-reinforced foamed concrete core. Mechanical properties of both plain and polyvinyl alcohol fibre-reinforced foamed concrete were obtained, which are needed for the design of sandwich panel and numerical modelling. It is found that the fibre-reinforcement largely enhances the mechanical behaviour of foamed concrete and composite sandwich panels. Finite element code Abaqus/Standard was employed to investigate the influence of face/core bonding and fastening on the four-point bending response of the sandwich panels. It was found that face/core bonding plays a crucial role in the structural performance while the influence of fastening is negligible.
\end{abstract}

Keywords: foamed concrete; fibre reinforcement; sandwich panel; structural behaviour; finite element simulation; face/core bonding

*Corresponding author: Tel.: +44 161 3065740, fax: +44 1613063849

E-mail: qingming.li@manchester.ac.uk 


\section{Introduction}

Foamed concrete is a type of cellular solid comprised of cement mortar matrix and air-void of minimum $20 \%$ in volume. It is made by incorporating air-voids into the cement matrix using pre-formed foam. Foamed concrete is a lightweight, low cost and easy-tomanufacture material with good workability and excellent performance on thermal insulation, acoustic insulation, fire resistance, corrosion resistance and shock absorption [1-4]. However, foamed concrete is not used as structural material due to its low compressive strength.

Inclusion of fine aggregates in the mortar matrix to improve the mechanical properties of foamed concrete has been investigated by several researchers [2, 3]; however, studies of the use of fibre-reinforcement in foamed concrete are very limited. Zollo [5] and Zollo and Hays [6] reported that polypropylene fibre-reinforced cellular concrete with density of 640 $\mathrm{kg} / \mathrm{m}^{3}$ presented a significant improvement of mechanical and impact properties. It was shown that the fibre reinforcement can change the typical brittle behaviour of cellular concrete into ductile elastic-plastic behaviour [6], which has been also observed for lightweight concrete reinforced by steel fibres [7]. Jones and McCarthy [2] reported that the compressive strength of polypropylene fibre-reinforced foamed concrete exhibited an increase of 52\% when compared to the unreinforced foamed concrete. High-performance fibres have also been used to reinforce lightweight concrete. Arisoy and $\mathrm{Wu}[8,9]$ used polyvinyl alcohol fibres as reinforcement for aerated concrete with density of 800-1600 $\mathrm{kg} / \mathrm{m}^{3}$. They found that the fibre-reinforced aerated concrete showed increases of flexural strength, flexural ductility and toughness when compared to plain aerated concrete.

The capacity of foamed concrete in structural applications has not been fully investigated. Due to its low density and low strength characteristics, it is an ideal core material for composite sandwich structures. Othuman Mydin and Wang [10] studied sandwich panels made with profiled thin steel face sheets $(0.4 \mathrm{~mm}$ thickness) and foamed concrete core under uniaxial compression. Uddin et al. [11] investigated the flexural behaviour of composite panels made with carbon fibre reinforced polymer face sheets and autoclaved aerated concrete core. It was found that the flexural strength of the panels is increased considerably when compared to the strength of the autoclaved aerated concrete.

This research is motivated by the lack of knowledge in the study of fibre-reinforced foamed concrete and composite sandwich panels with foamed concrete core for structural applications. In this work, tensile and compressive properties of plain foamed concrete and polyvinyl alcohol fibre-reinforced foamed concrete are presented. Two different methods are used to obtain compressive properties of foamed concrete and their results are discussed. Sandwich panels with corrugated steel faces and either plain or fibre-reinforced foamed concrete core are studied. The behaviour of the sandwich panels in four-point bending test is described and the various failure mechanisms observed in the test are reported. Finite element method was employed to understand the influence of face/core bonding and fastening on the four-point bending response of the sandwich panels. Materials and experimental details are described in Section 2. The experimental results and discussion are presented in Section 3. Numerical simulations are described in Section 4, which is followed by conclusions in Section 5. 


\section{Materials and methods}

\subsection{Foamed concrete}

The foamed concrete mix design used in this study is shown in Table 1. The mixture was prepared using ordinary Portland cement, sand, water and foam. The mixture in Table 1 is referred as plain foamed concrete (PFC). Fibre-reinforced foamed concrete (FRFC) was prepared using the same mix design in Table 1 and 3.3\% volume fraction of polyvinyl alcohol (PVA) fibre. Dry density of $1000 \mathrm{~kg} / \mathrm{m}^{3}$ was targeted in this study for both PFC and FRFC. The actual density of the samples was measured.

Table 1 Mix constituent proportions of foamed concrete for $1 \mathrm{~m}^{3}$.

\begin{tabular}{ll}
\hline Constituent material & Content \\
\hline Cement $(\mathrm{kg})$ & 539.58 \\
Dry sand $(\mathrm{kg})$ & 269.79 \\
Water $(l)$ & 269.79 \\
Foaming agent $(l)$ & 0.74 \\
Water for foaming agent $(l)$ & 25 \\
Foam required in the mix $(l)$ & 469.96 \\
\hline
\end{tabular}

\subsection{Foamed concrete preparation}

Foamed concrete is prepared in a procedure consisting of three stages, i.e., (i) slurry preparation, (ii) foam preparation, and (iii) mixing of slurry and foam. The slurry was prepared from ordinary Portland cement, sand and water mixed in a 300-litre cement mixer. Water:cement ratio of 0.5 and sand:cement ratio of 0.5 were used (Table 1 ). The wet density of the slurry was $2036 \mathrm{~kg} / \mathrm{m}^{3}$. The foam was prepared separately using EABASSOC foaming agent and a foam generator Portafoam PM2 system. To prepare the foam, the foaming agent is added to the water in the quantities indicated in Table 1 . This mixture is then poured in the foam generator container. The container is pressurised to $0.414 \mathrm{MPa}$ (60 psi) which produces a foam density of $70-80 \mathrm{~kg} / \mathrm{m}^{3}$. Finally, the foam is poured into the mixer until a targeted wet density of $1150 \mathrm{~kg} / \mathrm{m}^{3}$ is achieved. For FRFC, 8-mm PVA fibres with diameter of $0.04 \mathrm{~mm}$ supplied by Kuraray Co were used. PVA fibre properties from the manufacturer are shown in Table 2 [12]. The FRFC was prepared using the same aforementioned procedure for PFC with 3.3\% volume fraction of PVA fibre added to the slurry.

Table 2 Polyvinyl alcohol fibre properties from the manufacturer [12].

\begin{tabular}{llllll}
\hline $\begin{array}{l}\text { Diameter } \\
(\mathrm{mm})\end{array}$ & $\begin{array}{l}\text { Length } \\
(\mathrm{mm})\end{array}$ & $\begin{array}{l}\text { Density } \\
\left(\mathrm{kg} / \mathrm{m}^{3}\right)\end{array}$ & $\begin{array}{l}\text { Tensile strength } \\
(\mathrm{GPa})\end{array}$ & $\begin{array}{l}\text { Young's } \\
(\mathrm{GPa})\end{array}$ & Modulus \\
\hline 0.04 & 8 & 1260 & 1.6 & 40 & \\
\hline
\end{tabular}

\subsection{Mechanical characterisation of foam concrete}

Due to the brittle nature of foamed concrete, two different tests were performed to obtain compressive properties, i.e., (i) uniaxial compression test, and (ii) indentation test for both PFC and FRFC. In addition, tensile properties were obtained using dog-bone shaped 
specimens tested in uniaxial tension. All specimens were left to cure for at least 28 days before testing.

\subsubsection{Uniaxial compression test}

Uniaxial compression tests were performed according to BS-EN-12390 using an Instron servo-hydraulic machine at fixed displacement rate of $5 \mathrm{~mm} / \mathrm{min}$. Three cubes with dimensions of $100 \times 100 \times 100 \mathrm{~mm}$ were tested.

\subsubsection{Indentation test}

For indentation tests, three cylinders of $100 \mathrm{~mm}$ thickness and diameter of $150 \mathrm{~mm}$ were manufactured. A 20-mm diameter flat nosed indenter was mounted in an Instron servohydraulic machine and the load was applied at a nominal displacement rate of $5 \mathrm{~mm} / \mathrm{min}$. The indentation test allows for the tested material to be confined by the surrounding material whilst the compression load is being applied.

\subsubsection{Uniaxial tensile test}

Tensile tests were performed using dog-bone shaped specimens which are $75 \mathrm{~mm}$ long and have a cross-section area of $25 \times 45 \mathrm{~mm}$. The specimens were placed in the testing machine shown in Fig.1 and loaded in direct tension until failure. The load was applied at a constant displacement rate of $3 \mathrm{~mm} / \mathrm{min}$.

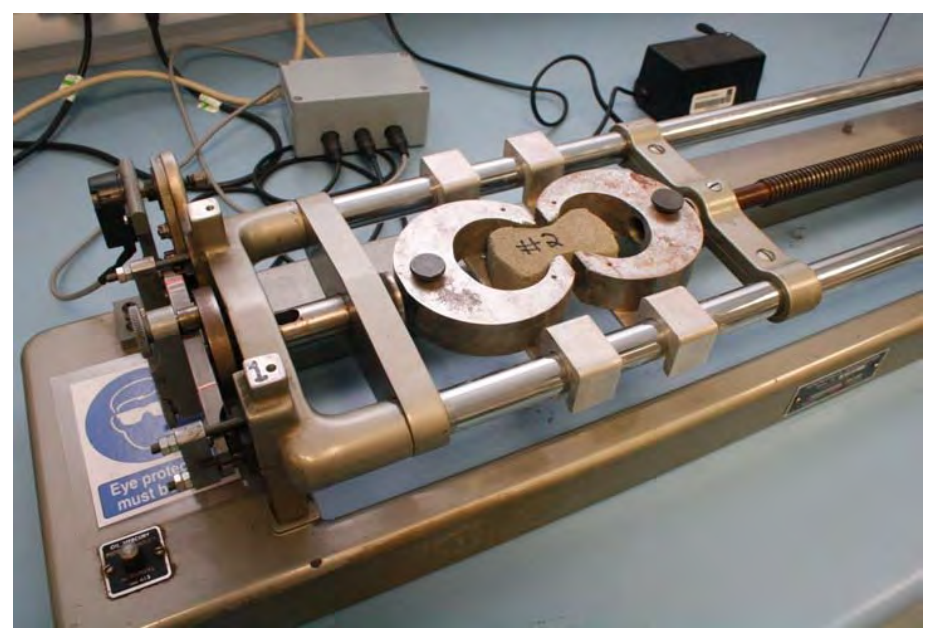

Figure 1 Tensile test set-up.

\subsection{Sandwich panel preparation}

Full scale composite sandwich panels were manufactured in-house using either PFC or FRFC as core and $0.7 \mathrm{~mm}$ thick corrugated steel sheets with a 1000/32 (cover width: 1000 $\mathrm{mm}$, profile height: $32 \mathrm{~mm}$ ) face profile. The geometrical details of the sandwich panel and corrugated steel sheet are described in Fig.2. To fabricate the sandwich panels, a mould containing both faces was manufactured. As the bonding between the faces and core was not aided by using adhesives, fasteners were applied as shown in Fig.2. This would help to improve the face/core bonding developed naturally during curing and also help in keeping the 
face sheets at the required distance during casting. Nine 10-mm diameter fasteners were used as indicated in Fig.2. Foamed concrete was prepared as described in Section 2.2 and cast into the mould. Sandwich panels were left for 28 days for curing in order to develop the core/face bonding and allow the core to reach maximum strength. Two specimens of each type were fabricated: specimens \#1 and 2 with PFC core and specimens \#3 and 4 with FRFC core.

a)
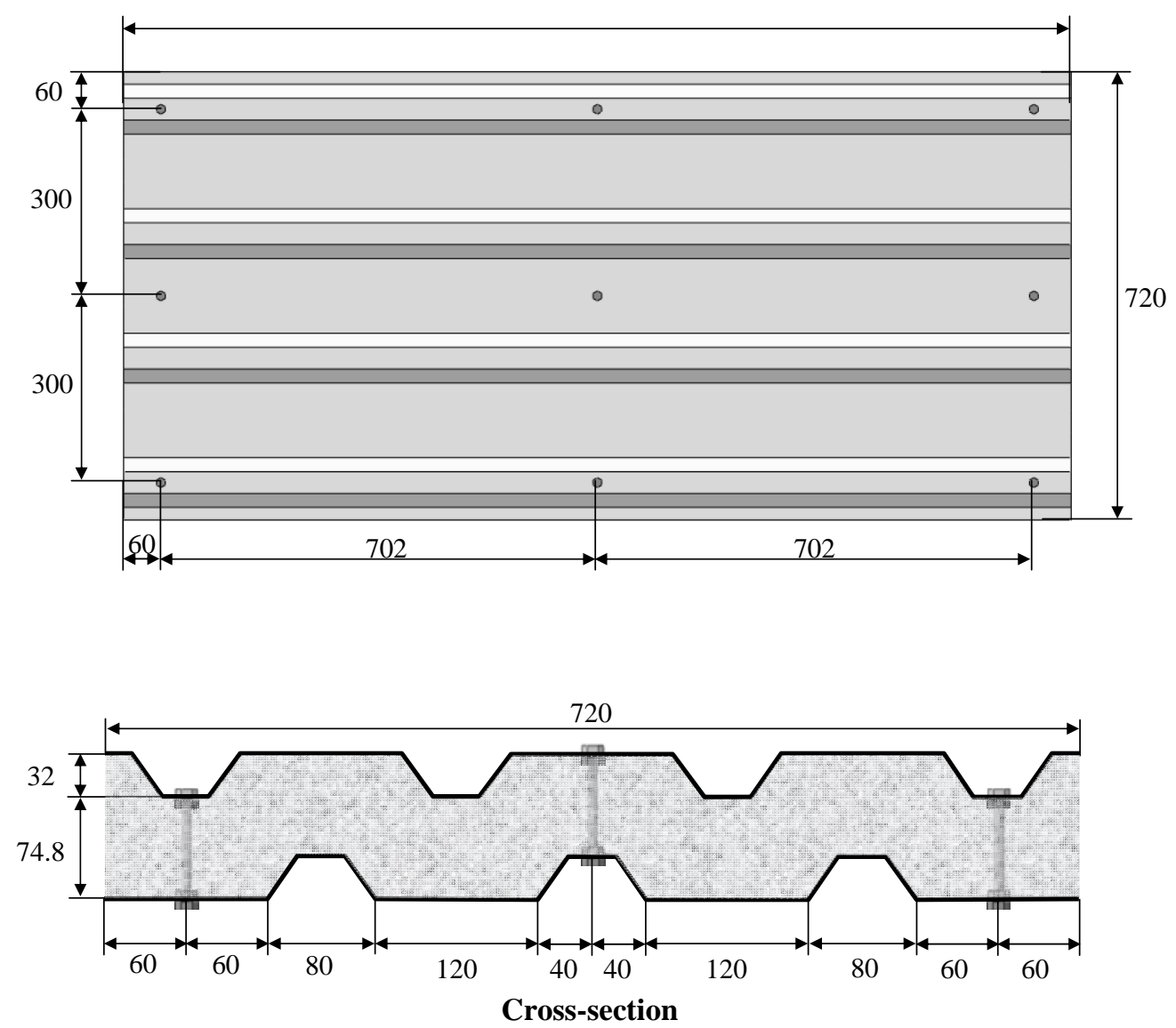

b)

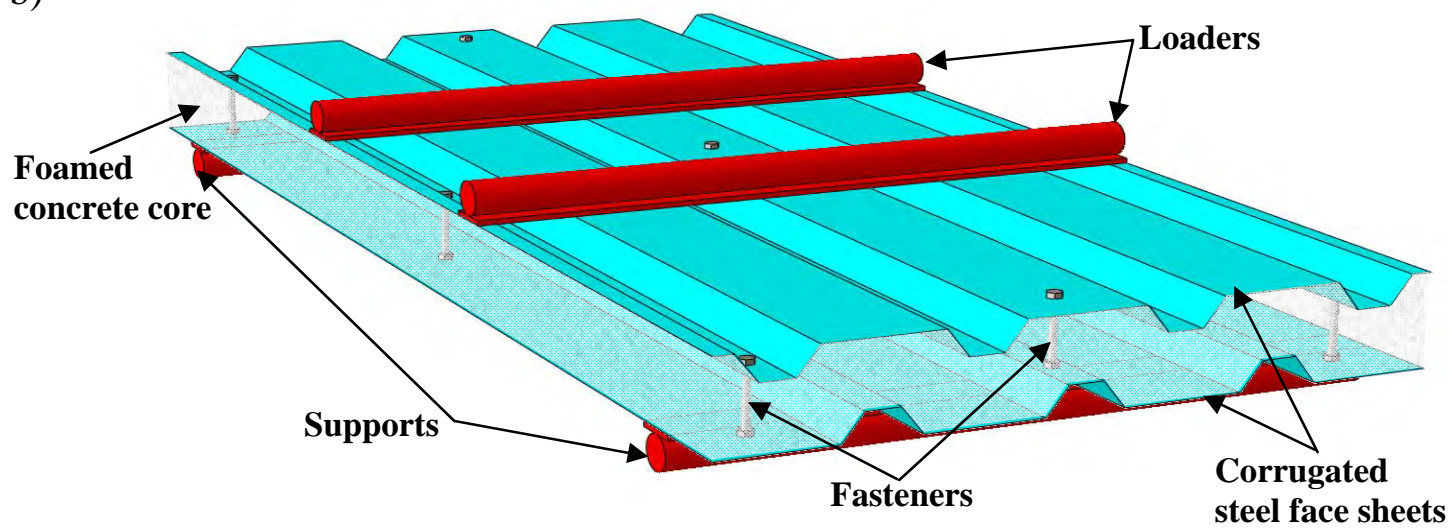

Figure 2 a) Geometrical details of sandwich panels and face sheets (dimensions are in $\mathrm{mm}$ ), b) schematic drawing of sandwich panel. 


\subsection{Sandwich panels in four-point bending}

Four-point bending tests were conducted on sandwich panel specimens using a universal testing machine with a $200 \mathrm{kN}$ load cell. A special rig was designed to perform the test, which consists of a loading frame attached to the loading machine with two loaders and a supporting frame with two supports, as shown in Fig.3. The distance between the two loaders is $434 \mathrm{~mm}$ and the distance between the two supports is $1300 \mathrm{~mm}$. The load was applied at a constant displacement rate of $0.5 \mathrm{~mm} / \mathrm{min}$ at room temperature $\left(23^{\circ} \mathrm{C} \pm 3^{\circ} \mathrm{C}\right)$ and relative Humidity of $50 \% \pm 5 \%$. After the failure of the specimen, the load was applied at a displacement rate of $3 \mathrm{~mm} / \mathrm{min}$. The specimen was loaded until its mid-span deflection reached $60 \mathrm{~mm}$. The deflection of the top face was measured from the crosshead displacement while the deflection of the bottom face was measured using a linear variable differential transformer (LVDT) that was installed at mid-point of the specimen. The data from both the testing machine and LVTD were compiled by a computer. The complete test set-up is shown in Fig.3. To prevent local crushing of the core, steel strips with $50 \mathrm{~mm}$ width were placed under the loaders and above the supports (Fig.3).

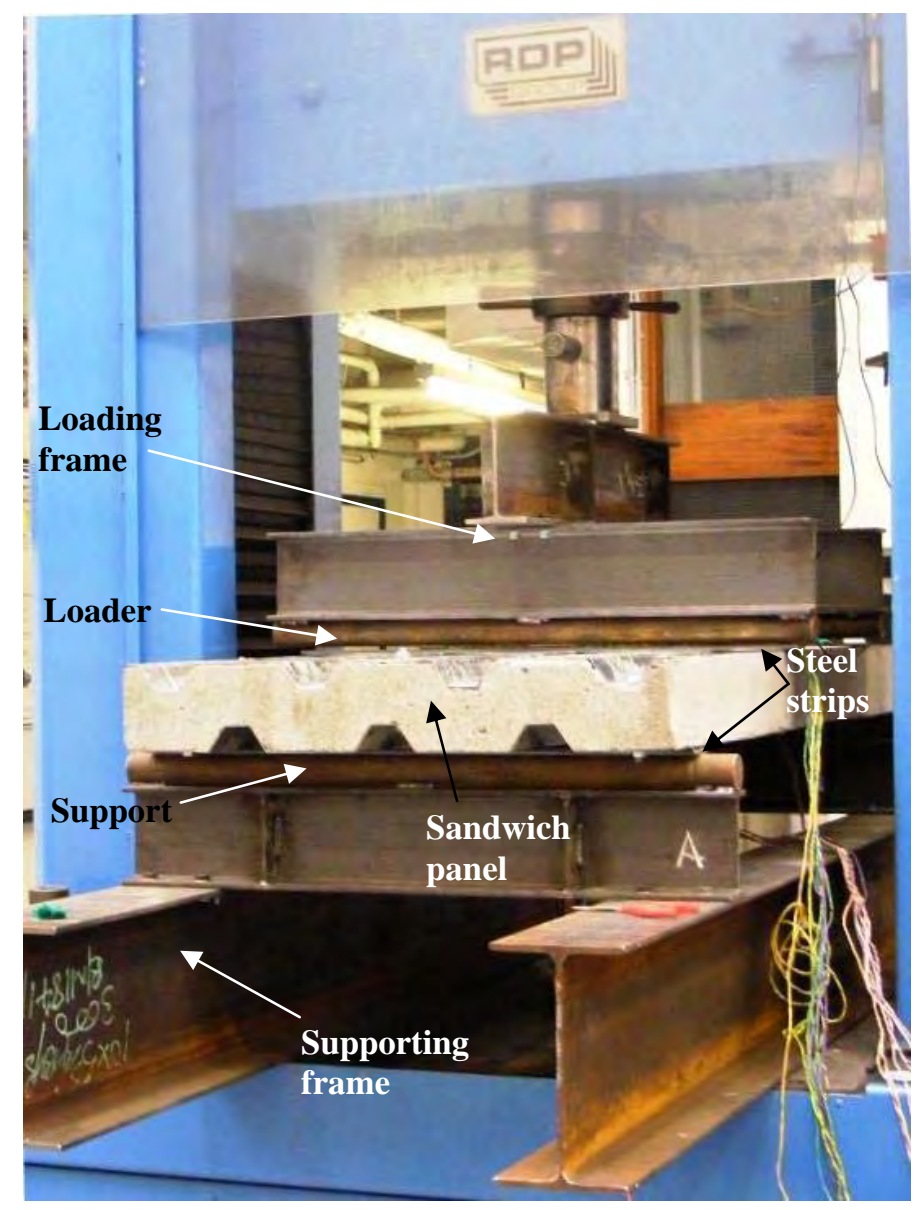

Figure 3 Four-point bending test set-up. 


\section{Results and discussion}

The average densities of the PFC and FRFC after 28 days of curing were 990.17 $\mathrm{kg} / \mathrm{m}^{3}$ and $1054.8 \mathrm{~kg} / \mathrm{m}^{3}$, respectively, for both material testing specimens and sandwich panel cores. These densities are comparable, both within $5.5 \%$ of the target density of 1000 $\mathrm{kg} / \mathrm{m}^{3}$.

\subsection{Uniaxial compression test}

Figures $4 \mathrm{a}$ and $4 \mathrm{~b}$ show typical stress-strain curves under uniaxial compression for PFC and FRFC, respectively. An initial elastic response at very low strains is observed in both foamed concretes until a peak stress is reached followed by a sudden drop in stress, which corresponds to the failure of the specimen. It can be seen that FRFC exhibits higher compressive strength when compared to PFC which is attributed to the enhancement of the FRFC specimen integrity by the fibres. It can also be seen in Fig.4b that two of the FRFC specimens entered into the densification regime, which is a common feature of cellular solids $[13,14]$. The measured densification strain from specimens $\# 1$ and 2 is $\varepsilon_{D}=0.52 \pm 0.077$. The development of the densification regime is attributed to the maintenance of specimen integrity by fibres after failure. This is in contrast to the brittle behaviour of PFC specimens, which completely fell to pieces at strain of 0.2 . Table 3 shows the mechanical properties obtained from Fig.4. Increases of $22.6 \%$ and $84.7 \%$ were observed in the compressive modulus and strength, respectively, for FRFC when compared with PFC.
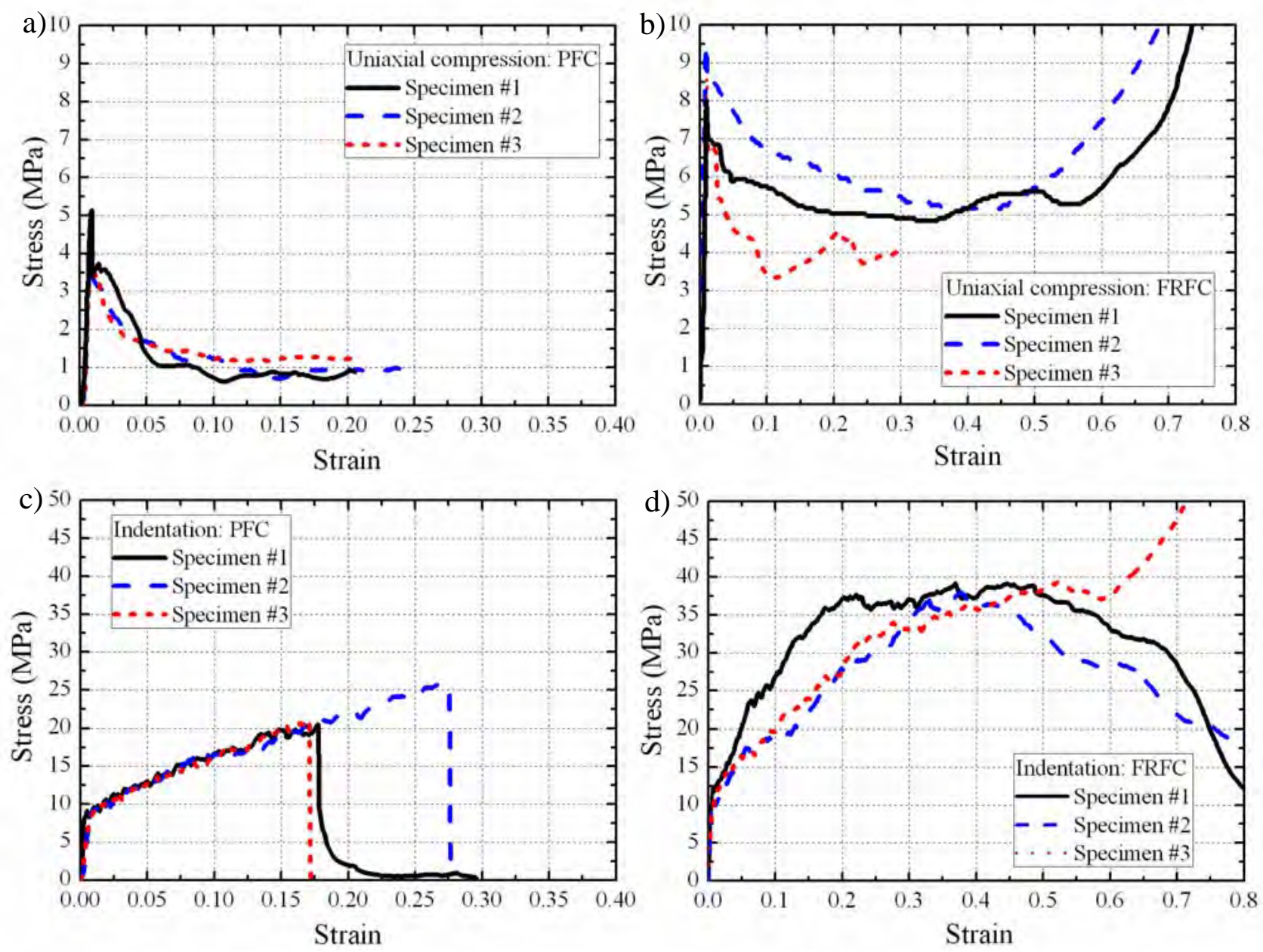

Figure 4 Typical uniaxial compression stress-strain curves for a) PFC and b) FRFC; indentation test stress-strain curves for c) PFC and d) FRFC. 
Table 3 Mechanical properties of PFC and FRFC.

\begin{tabular}{lll}
\hline Properties & PFC & FRFC \\
\hline Uniaxial compression elastic modulus (MPa) $E$ & $1002.19 \pm 60.47$ & $1228.93 \pm 59.45$ \\
Uniaxial compression strength $(\mathrm{MPa}) \sigma_{c}$ & $4.78 \pm 0.57$ & $8.83 \pm 0.35$ \\
Uniaxial compression yield strain $(\%) \varepsilon_{y c}$ & $0.84 \pm 0.06$ & $0.95 \pm 0.008$ \\
Indentation compressive elastic modulus $(\mathrm{MPa}) E_{i}$ & $1358.67 \pm 106.79$ & $2148.8 \pm 131.85$ \\
Indentation compressive strength $(\mathrm{MPa}) \sigma_{c i}$ & $9.34 \pm 0.3$ & $11.17 \pm 1.58$ \\
Indentation compressive yield strain $(\%) \varepsilon_{y i}$ & $1.44 \pm 0.1$ & $0.67 \pm 0.05$ \\
Tensile elastic modulus (MPa) $E_{t}$ & $3.48 \pm 0.09$ & $9.34 \pm 1.1^{*}$ \\
Tensile strength (MPa) $\sigma_{t}$ & $0.272 \pm 0.018$ & $1.79 \pm 0.22 *$ \\
Tensile yield strain $(\%) \varepsilon_{y t}$ & $8.15 \pm 0.21$ & $20.75 \pm 1.06^{*}$ \\
\hline *note: specimen \#3 was not used in the measurements due to a premature failure. & &
\end{tabular}

\subsection{Indentation test}

Figures 4c and 4d show the stress-strain curves for PFC and FRFC, respectively, from the indentation tests. An initial elastic regime at very low strains is observed until a peak stress is reached, which indicates the onset of the plastic collapse and crushing of the cells. For PFC the compressive strength is higher than the one observed in uniaxial compression test (Table 3). This is due to the fact that the indenter not only crushes the foamed concrete cells but also tears the wall cells at the indenter perimeter and overcomes friction, which has been observed in the indentation test of polymeric foams [15]. This also explains the steady increase of stress or hardening in the plastic regime, which is more pronounced for FRFC because the indenter has to break and/or pull fibres during the indentation. For indentation, PFC specimens did not fail immediately at the onset of the plastic regime (as observed in uniaxial compression), but after certain indentation distance. It can also be observed in Fig.4d that one of the FRFC specimens also enter into the densification regime with a measured densification strain of $\varepsilon_{D}=0.58$. Mechanical properties obtained from indentation tests are shown in Table 3.

\subsection{Uniaxial tensile test}

Figures $5 \mathrm{a}$ and $5 \mathrm{~b}$ show the typical stress-strain curves from the uniaxial tensile test for PFC and FRFC, respectively. For PFC, only an elastic regime is observed until a peak stress is observed, which is followed by a sudden failure of the specimens. For FRFC, an initial elastic regime is observed until a peak stress is reached indicating the onset of the plastic region. In contrast to PFC specimens, fibres prevent a sudden failure of the specimen as observed in Fig.5b. For FRFC specimen \#3, premature failure of the specimen was observed, which is attributed to large voids formed during fabrication as confirmed in posttest observations. The mechanical properties from uniaxial tensile test are depicted in Table 3. It can be seen that the fibre-reinforcement drastically increases the tensile properties of the foamed concrete. Increases of $168.4 \%$ and $580.1 \%$ in the tensile modulus and strength were observed, respectively (Table 3). 

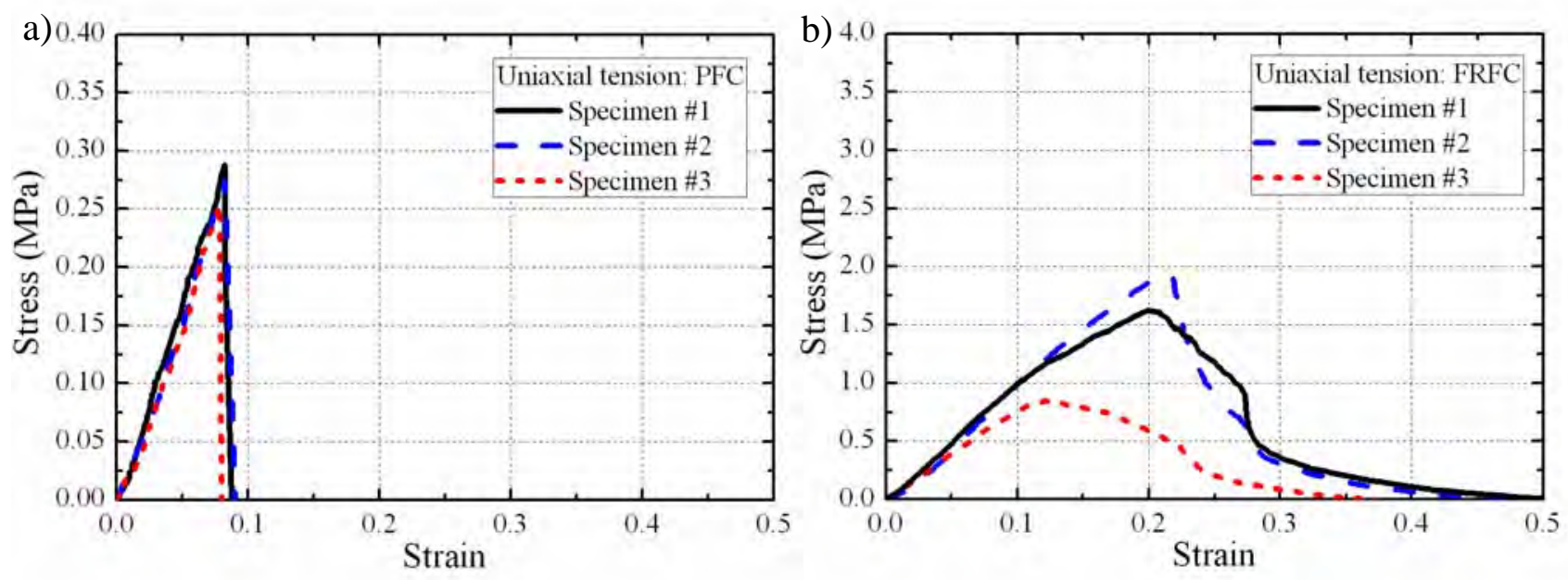

Figure 5 Typical uniaxial tension stress-strain curves for a) PFC and b) FRFC.

\subsection{Sandwich panels in four-point bending}

Figures 6a and 6b show typical load-displacement curves for PFC cored sandwich panel specimen \#1 and specimen \#2, respectively. An initial linear-elastic regime is observed until a shear crack occurred resulting in a sudden decrease of the load. The first shear crack was initiated in the bottom face of the sandwich panel directly under one of the loaders or very near to it (Fig.7a) indicating that the specimen failed by core shear failure. Further shear cracks followed the first one, all of them observed under the loaders. After a series of shear cracks, a plateau regime was observed, during which, the load was maintained. In this regime, the load was higher than the initial failure load resulting in an apparent strengthening of the sandwich panel. This is mainly due to the transfer of shear resistance from the weak core to the strong fasteners. Although foamed concrete core lost its shear resistance after failure, it still had the function to separate the face sheets to enable the further increase of the bending resistance of the sandwich panel. In the plateau regime, the further increase of the local contact force resulted in face wrinkling (Fig.7b) and face/core debonding (Fig.7b), which caused a degradation of structural integrity, leading to a subsequent failure stage characterised by the continuous decrease of load. In the failure stage, slippage of the bottom face (Fig.7c) was developed leading to high stress concentration on the fasteners at the corners of the sandwich panel and cracking (Fig.7d). It was also noted that some local face/core debonding was developed during the curing process at certain areas of sandwich panels prior to testing as shown in Fig.7e; however, the extension of the debonding was not known. The effects of the face/core debonding on the sandwich panel performance are studied numerically in Section 4. Failure loads and displacements at failure for both specimens are shown in Table 4. Variations of failure load and displacement at failure are attributed to small difference in the dry density of the specimens and difference of face/core debonding in the specimens.

Figures 6c and 6d show load-displacement curves for FRFC cored sandwich panel specimen \#3 and specimen \#4, respectively. The initial stage of the loading curves was linearelastic followed by a sudden drop of the force due to tension cracking. In contrast to PFC cored specimens, only a single crack was observed in the mid-section of the specimen (Fig.7f) indicating that the sandwich plate failed by core tension, and possibly core/face 
debonding in certain areas, which lead to a sudden drop of the applied force. Loads and displacements at failure for both specimens are shown in Table 4. A plateau-like regime with a slight decrease of the force was observed after the first tension crack. In this regime, similar failure mechanism to those observed for PFC cored panels were observed, i.e, slippage, debonding and wrinkling. For specimen \#4, a smooth drop of the load was observed at 20mm displacement which corresponds to a shear crack observed directly under one of the loaders (Fig.7f).

Table 4 shows the peak failure load and top face deflection at failure of sandwich panels from Fig.6. Increases of $98.31 \%$ and $100.75 \%$ in the average peak failure load and deflection at failure were observed, respectively, for FRFC core when compared to PFC core. An increase of $21.12 \%$ in the average load at $30-\mathrm{mm}$ top face deflection was also observed in the plateau regime for FRFC when compared to PFC. However, for PFC cored sandwich specimens the average load in the plateau regime was higher than the average peak failure load showing a strengthening of the specimens after failure, while for FRFC cored sandwich specimens the average load at 30 -mm deflection in the plateau-like regime was $65.28 \%$ of the average peak failure load. As discussed previously, this difference is caused by the increase of core strength (both tensile and compressive strengths) of the FRFC, which leads to the change of failure mode. These observations are important from a design point of view because they suggest that a higher factor of safety should be considered when FRFC is used as core in sandwich structures.
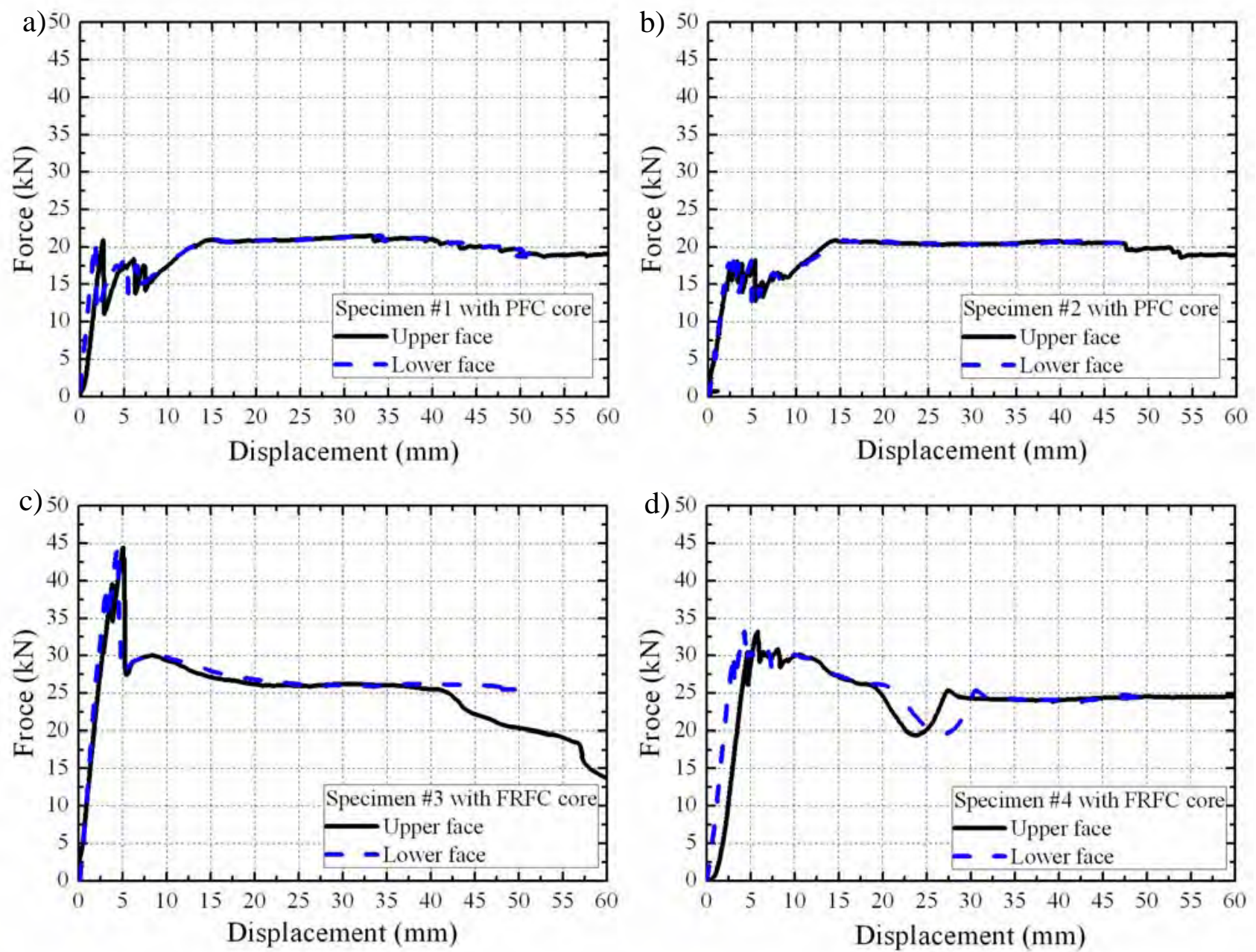

Figure 6 Typical load-displacement curves for sandwich panels with PFC core: a) specimen \#1, b) specimen \#2; and with FRFC core: c) specimen \#3, d) specimen \#4. 
a)

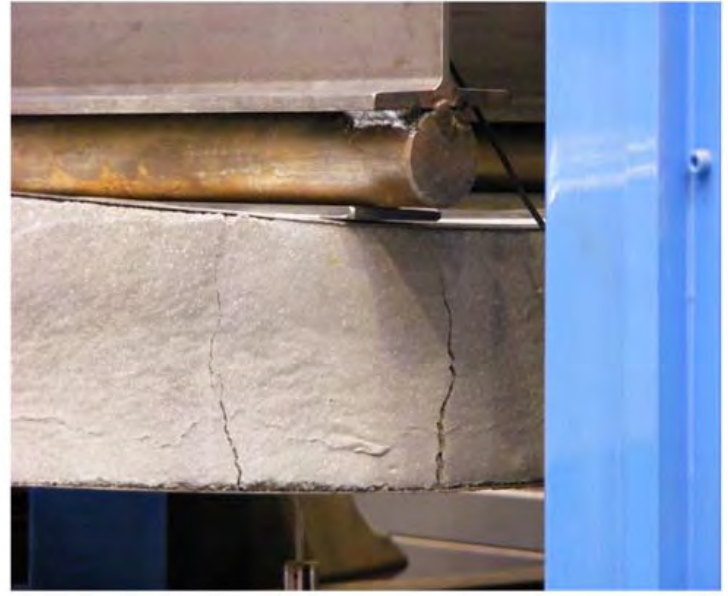

c)

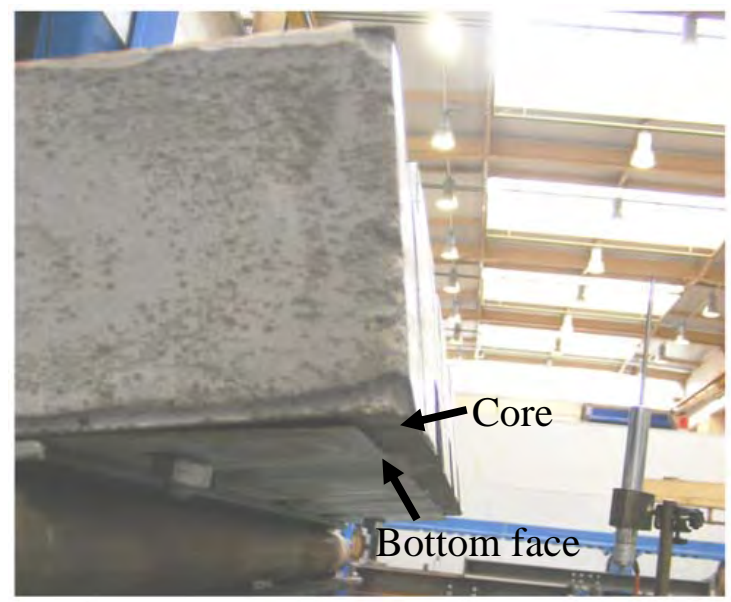

e)

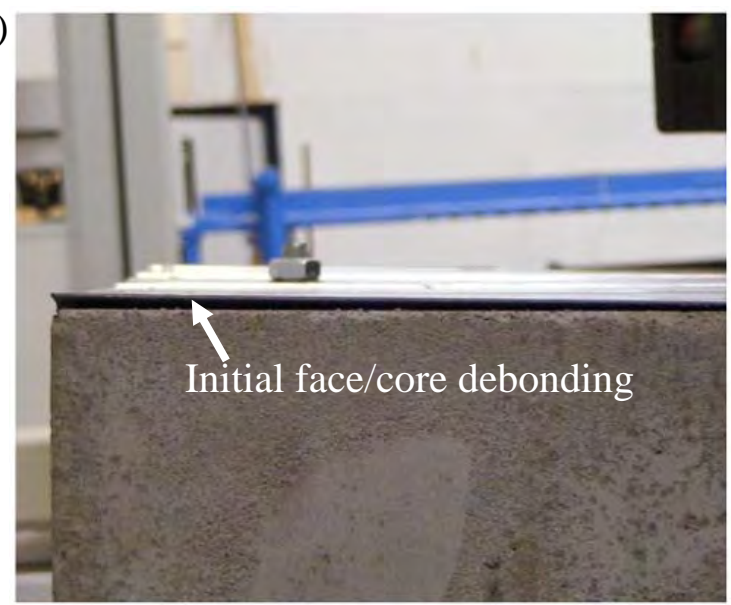

b)

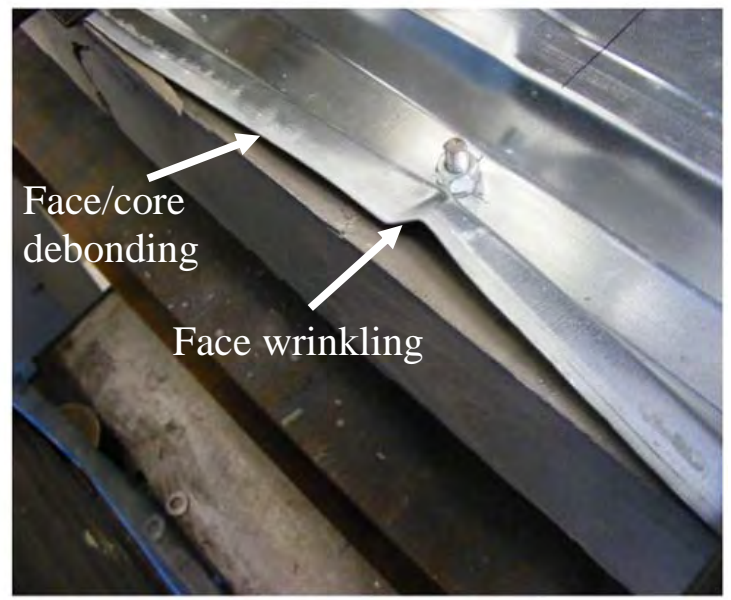

d)

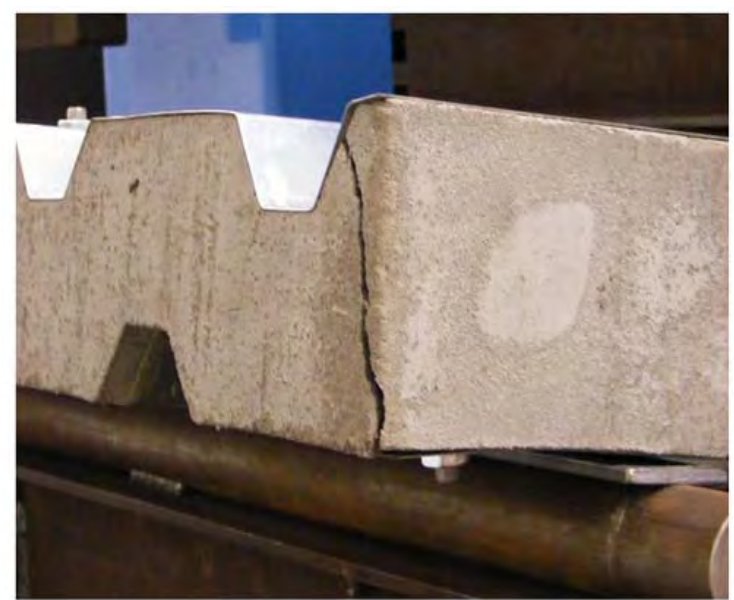

f)

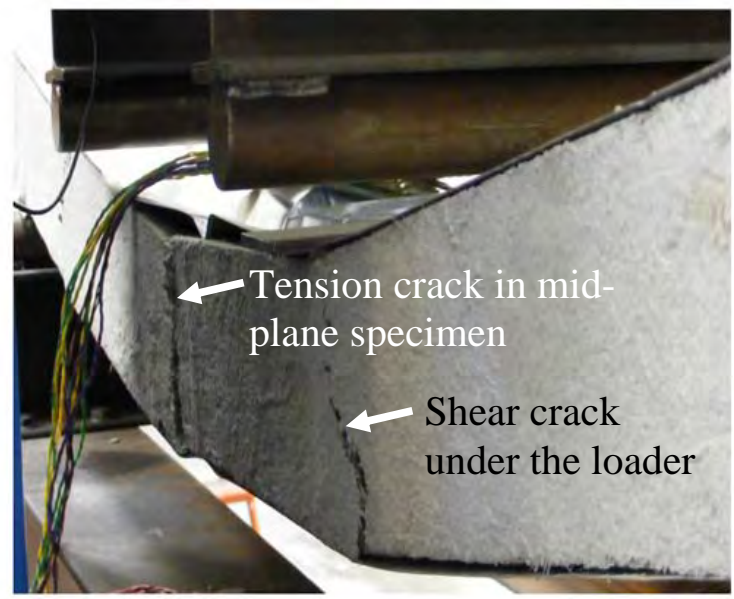

Figure 7 Failure modes observed during four-point bending of sandwich panels: a) core shear failure under the loader, b) face wrinkling and face/core debonding, c) slippage of the bottom face, d) cracking around the fastener, e) initial face/core debonding, f) core tensile failure in the mid-plane of the specimen and core shear failure under the loader for specimen \#4. 
Table 4 Peak failure load, top face deflection at failure and load at 30-mm top face deflection of sandwich panels from Fig.6.

\begin{tabular}{llll}
\hline Sandwich specimen & Peak failure load $(\mathrm{kN})$ & $\begin{array}{l}\text { Top face deflection } \\
\text { at failure }(\mathrm{mm})\end{array}$ & $\begin{array}{l}\text { Load at 30-mm top face } \\
\text { displacement }(\mathrm{kN})\end{array}$ \\
\hline Specimen \#1 PFC core & 20.96 & 2.61 & 21.26 \\
Specimen \#2 PFC core & 18.02 & 2.73 & 20.39 \\
Average & 19.49 & 2.67 & 20.83 \\
Standard deviation & 2.08 & 0.08 & 0.62 \\
\hline Specimen \#3 with FRFC core & 44.38 & 5.08 & 26.19 \\
Specimen \#4 with FRFC core & 32.92 & 5.64 & 24.26 \\
Average & 38.65 & 5.36 & 25.23 \\
Standard deviation & 8.10 & 0.40 & 1.36 \\
\hline
\end{tabular}

\section{Numerical simulations}

Finite element simulation of sandwich panels in four-point bending were performed using Abaqus/Standard commercial code [16]. Numerical simulation was employed as a tool to understand the effects of face/core bonding and fasteners on the structural behaviour of the sandwich panels, which were not investigated experimentally due to the limited number of tests available. The problem was considered to be symmetric such that only a half model was built as a three-dimensional solid, as shown in Fig.8. The mesh comprises 8-node brick elements (C3D8R) for the core, loader and support, 4-node shell elements (S4R) for the face sheets and 2-node truss elements (T3D2) for the fasteners (Fig.8). All elements used reduced integration formulation. Loader and support were modelled as rigid bodies. A total of 7296, 6688 and 54720 elements were used for the top face, bottom face and core, respectively. Nine elements were used for each fastener, which were embedded in the core elements using the Embedded Region Constraint option. The ends of the fasteners were tied to the face sheets using the Tie Constraint option. The average element size was $10 \mathrm{~mm}^{3}$ for brick elements, 10 $\mathrm{mm}^{2}$ for shell elements and $10 \mathrm{~mm}$ for truss elements. A finer mesh was also tested, which did not show any significant variation in the load response, but a significant increase in computational time. Contact was modelled using finite sliding formulation and surface to surface discretisation method.

Steel face sheets were modelled using an isotropic elastic-perfectly plastic material model available in Abaqus/Standard with following material parameters: Young's Modulus $E=210 \mathrm{GPa}$, yield stress $\sigma_{y}=186 \mathrm{MPa}$, Poisson's ratio $\nu=0.3$ and density $\rho=7800 \mathrm{~kg} / \mathrm{m}^{3}$. The elastic behaviour of the foamed concrete core was modelled using uniaxial compression elastic modulus and yield stress from Table 3, $v=0.1$ and density of $1000 \mathrm{~kg} / \mathrm{m}^{3}$. The plastic behaviour was modelled using the crushable foam material model with following parameters: compression yield stress ratio $k=1$ and hydrostatic yield stress ratio $k_{t}=0.1$, where $\mathrm{k}=\sigma_{c} / p_{c}$ and $k_{t}=p_{t} / p_{c} ; p_{t}$ and $p_{c}$ are the hydrostatic tensile strength of the foamed concrete and its yield stress in hydrostatic compression, respectively. Abaqus user's manual [16] recommends that $k_{t}=0.1$. However, experimental observation in Li et al. [17] suggested that $k_{t}$ may be larger than 0.1. Numerical simulations were performed in this study using both $k_{t}=0.1$ and $k_{t}=1$ for comparison; however, there was no significant difference in the results, which confirms that 
the material response is dominated by compressive stress, and therefore is insensitive to the value of $k_{t}$ [17]. It is assumed that foamed concrete core would not behave in a brittle fashion due to confinement and for this reason perfectly-plastic behaviour is adopted for the crushable foam hardening in Abaqus/Standard. It was not necessary to model the densification regime of the foamed concrete since the comparison between simulations and experiments is restricted to 8-mm deflection due to the lack of fracture parameters to simulate the failure of the specimen.

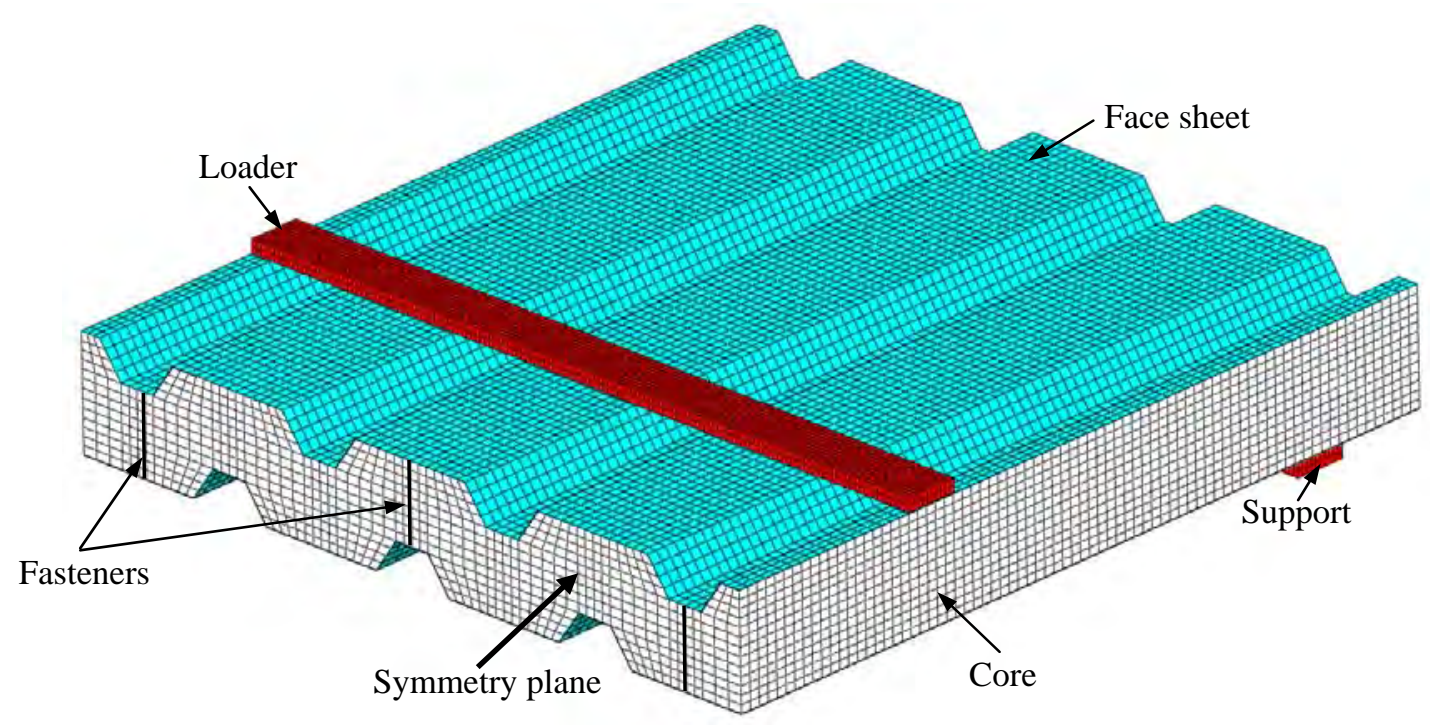

Figure 8 Finite element mesh of 3-D model.

\subsection{Effect of the face/core bonding}

Local face/core debonding was observed prior testing in sandwich specimens as aforementioned in Section 3.4 (Fig.7e). To assess the effect of the face/core debonding, two extreme cases were considered for the boundary conditions of the sandwich panel, i.e., case 1: fully-bonded (Tie Constraint option between faces and core) and case 4: fully-debonded (only contact between faces and core); two partial-bonding cases were also considered by using Tie Constraint option only in fasten areas (Cases 2 and 3 in Fig.9).

Figure 10a shows a comparison between experimental results and numerical simulations for all cases aforementioned and for PFC foam cored sandwich panels. It can be seen that for case 1 (fully-bonded), the model largely overestimates the load response of the sandwich panel by over-predicting the stiffness. This can be explained by the fact that there was some initial face/core debonding prior to testing which reduced the stiffness of the panel. It can also be observed that case 4 (fully-debonded) largely underestimates the loading response of the panels. This is due to the fact that the faces were partially-bonded to the core rather than fully-debonded. It can also be seen that experimental response lies between the predicted responses for cases 2 and 3 (partially-bonded) indicating that the extension of the debonding in the specimen is similar to those of cases 2 and 3. Figure 10b shows a 
comparison between experimental results and numerical simulations for FRFC cored sandwich panels. It can be seen that the trend observed in Fig.10a for PFC core are also observed for FRFC core, i.e., experimental response is close to the predicted responses for partially-bonded cases.

These aforementioned findings are very important from a design point of view since they show that bonding between faces and foamed concrete core plays a crucial role in the performance of the structure prior to failure. This means that, to obtain the maximum structural performance of the panels, face/core bonding must be improved. Shear connectors may be used to improve the structural performance and increase face/core bonding, which include shear studs, T-connectors and perfobond rib connectors [18, 19]. Epoxy resin adhesives may be another viable option for the improvement of the face/core bonding [20]. However, further investigation (both experimental and numerical) should be performed to assess the effectiveness of these options on foamed concrete cored sandwich structures.

a) Case 2

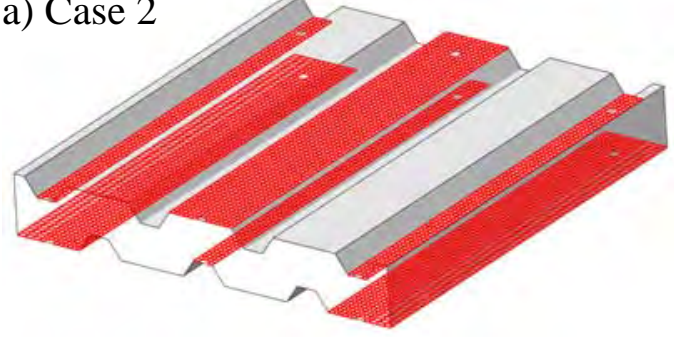

b) Case 3

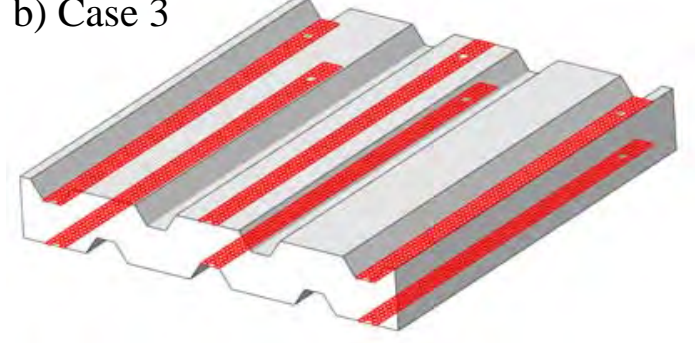

Figure 9 Fasten areas using Tie Constraint option for partially-debonded cases: a) Case 2 and b) Case 3.
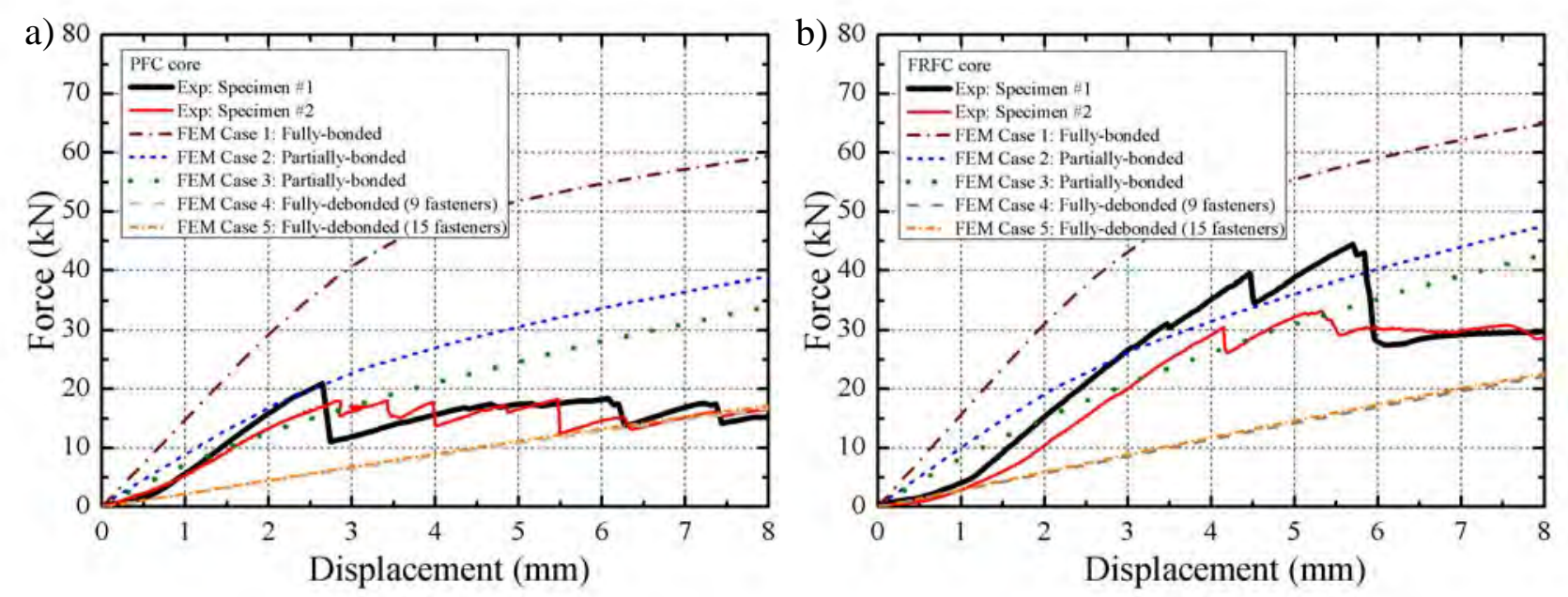

Figure 10 Comparison of experimental and numerical results of sandwich panels in four-point bending: a) PFC core, b) FRFC core. 


\subsection{Effect of the fastening}

The effect of the number of fasteners on the performance of the sandwich panels was studied by adding 3 more fasteners to the half model in the plane located at $301 \mathrm{~mm}$ from the mid plane, which is equivalent to adding 6 more fasteners to the whole structure (Case 5). Full-debonding conditions were used in the simulation. It can be seen in Fig.10 that the effect of adding more fasteners is insignificant when compared to the effect of increasing the bonded area between faces and core.

\section{Conclusions}

Compressive mechanical properties of plain foamed concrete and polyvinyl alcohol fibre-reinforced foamed concrete were obtained using uniaxial compression test and indentation test. It is found that the fibre-reinforcement enhances the compressive strength of foamed concrete, which is attributed to the increase of specimen integrity by the fibres. A densification regime was observed in the compressive test of fibre-reinforced specimens, which is also attributed to the maintenance of specimen integrity by the fibres after failure. Tensile mechanical properties were obtained using uniaxial tensile test. It is found that the fibre-reinforcement drastically increases the tensile modulus, strength and yield strain of the foamed concrete and also prevents a sudden failure of the specimens, which is in contrast to the brittle behaviour of plain foamed concrete specimens.

Full-scale specimens with corrugated steel sheet faces and either plain foamed concrete core or fibre-reinforced foamed concrete core were manufactured and tested in fourpoint bending. It is found that the fibre-reinforcement improves the structural response of composite sandwich panels by increasing the maximum load-carrying capacity before the failure of the specimen; however, for sandwich specimens with plain foamed concrete core, the average load in the plateau regime was higher than the average peak failure load showing an apparent strengthening of the specimens after failure. For fibre-reinforced foamed concrete cored sandwich specimens, the average load in the plateau-like regime is $65.28 \%$ of the average peak failure load. Such difference should be considered when fibre-reinforced foamed concrete is used in sandwich structural constructions.

Numerical simulations of foamed concrete cored sandwich panels in four-point bending were performed using Abaqus/Standard finite element code. It is found that face/core bonding plays a crucial role in the structural performance while the contribution of fastening is negligible. This indicates that improvement of the face/core bonding should be addressed when foamed concrete core is used to obtain optimum structural performance of composite sandwich panels.

\section{Acknowledgements}

We acknowledge the assistance from Michael Mercer-Fox and Akhil Rajagopal Kozhipuram in experimental work and John Mason from The University of Manchester for the manufacture of the specimens. The test was supported by a UK Minister of Defence TEAM MAST project (MAST/TIN001/INV229). 


\section{References}

[1] Narayanan N, Ramamurthy K. Structure and properties of aerated concrete: a review. Cem Concr Compos 2000;22(5):321-9.

[2] Jones MR, McCarthy A. Preliminary views on the potential of foamed concrete as a structural material. Mag Concr Res 2005;57(1):21-31.

[3] Ramamurthy K, Kunhanandan Nambiar EK, Indu Siva Ranjani G. A classification of studies on properties of foam concrete. Cem Concr Compos 2009;31(6):388-96.

[4] Othuman MA, Wang YC. Elevated-temperature thermal properties of lightweight foamed concrete. Constr Build Mater 2011;25(2):705-16.

[5] Zollo RF. Fiber-reinforced concrete: an overview after 30 years of development. Cem Concr Compos 1997;19(2):107-22.

[6] Zollo RF. Engineering material properties of a fiber reinforced cellular concrete. ACI Mater J 1998;95(5):631-5.

[7] Kayali O, Haque MN, Zhu B. Some characteristics of high strength fiber reinforced lightweight aggregate concrete. Cem Concr Compos

2003;25(2):207-13.

[8] Arisoy B, Wu H-C. Material characteristics of high performance lightweight concrete reinforced with PVA. Constr Build Mater 2008;22(4):635-45.

[9] Arisoy B, Wu H-C. Performance of a fibre-reinforced lightweight concrete panel. Proc Inst Civ Eng Constr Mater 2008;161(4):157-62.

[10] Othuman Mydin MA, Wang YC. Structural performance of lightweight steel-foamed concrete-steel composite walling system under compression. Thin Walled Struct 2011;49(1):66-76.

[11] Uddin N, Fouad F, Vaidya UK, Khotpal A, Serrano-Perez JC. Structural Characterization of Hybrid Fiber Reinforced Polymer (FRP)-Autoclave Aerated Concrete (AAC) Panels. J Reinf Plast Compos 2006;25(9):981-99.

[12] Kurakay Co, Technical: fibers, http://www.kuraray-am.com/pvaf/fibers.php, accessed on April 29, 2011.

[13] Flores-Johnson EA, Li QM, Mines RAW. Degradation of Elastic Modulus of Progressively Crushable Foams in Uniaxial Compression. J Cell Plast 2008;44(5):415-34.

[14] Li QM, Magkiriadis I, Harrigan JJ. Compressive Strain at the Onset of Densification of Cellular Solids. J Cell Plast 2006;42(5):371-92.

[15] Flores-Johnson EA, Li QM. Indentation into polymeric foams. Int J Solids Struct 2010;47(16):1987-95.

[16] Abaqus Analysis User's Manual, Version 6.9, Simulia, 2008.

[17] Li QM, Mines RAW, Birch RS. The crush behaviour of Rohacell-51WF structural foam. 2000;37(43):6321-41.

[18] Valente I, Cruz PJS. Experimental analysis of Perfobond shear connection between steel and lightweight concrete. J Constr Steel Res 2004;60(3-5):465-79.

[19] Valente IB, Cruz PJS. Experimental analysis of shear connection between steel and lightweight concrete. J Constr Steel Res 2009;65(10-11):1954-63.

[20] Vilnay O. The analysis of reinforced concrete beams strengthened by epoxy bonded steel plates. Int J Cem Compos Lightweight Concr 1988;10(2):73-8. 